\title{
Downregulation of a7 nicotinic acetylcholine receptors in peripheral blood monocytes is associated with enhanced inflammation in preeclampsia
}

\author{
Hongmei $\mathrm{Xu}^{1+}$, Qingyang Shi ${ }^{2+}$, Yanxiang $\mathrm{Mo}^{1}$, Linlin $\mathrm{Wu}^{1}$, Jishuang $\mathrm{Gu}^{1}$ and Ying $\mathrm{Xu}^{3^{*}}$ (D)
}

\begin{abstract}
Background: Preeclampsia is associated with chronic inflammation. The cholinergic anti-inflammatory pathway regulates systemic inflammation through activating a7 nicotinic acetylcholine receptors (a7nAChR) expressed in monocytes/ macrophages. This study aimed to investigate the role of a7nAChR in peripheral blood monocytes in preeclampsia.

Methods: Peripheral blood monocytes were isolated from 30 nonpregnant (NP), 32 normotensive pregnant (NT), and 35 preeclamptic (PE) women.

Results: We found that both protein and mRNA expression levels of a7nAChR in monocytes from the PE women were significantly lower than those of the NP and NT women (both $p<0.01$ ). a7nAChR protein expression levels in monocytes were negatively correlated with levels of systolic blood pressure $(r=-0.40, p=0.04)$, proteinuria $(r=-0.54, p<0.01)$, tumor necrosis factor-alpha (TNF- $a, r=-0.42, p=0.01$ ), and interleukin (IL)-1 $\beta(r=-0.56, p<0.01$ ), while positively correlated with IL-10 levels $(r=0.43, p=0.01)$ in the PE women. Both baseline and lipopolysaccharides (LPS)-induced increase of TNF-a, IL-1 $\beta$, and IL-6 levels from monocytes were higher in the PE group than the NP and NT groups (all $p<$ $0.01)$, but IL-10 levels in the PE group was lower than that of the NP and NT groups $(p<0.01)$. In addition, the NF-KB activity in monocytes from the PE women was higher than the NP and NT women $(p<0.01)$. Importantly, activation of a7nAChR with its agonist PNU-282987 inhibited NF-KB, decreased TNF-a, IL-1 $\beta$, and IL-6 release, and increased IL-10 release in monocytes from the PE women (all $p<0.01$ ).
\end{abstract}

Conclusion: In conclusion, these findings suggest that downregulation of a7nAChR may be associated with the development of preeclampsia through increasing pro-inflammatory and decreasing anti-inflammatory cytokine release via the NF-KB pathway.

Keywords: Preeclampsia, a7nAChR, Hypertension, Inflammation, NF-kB

\section{Introduction}

Preeclampsia is a common and serious condition during pregnancy, which is characterized by pregnancy-induced hypertension and proteinuria after 20 weeks of pregnancy. Approximately 5\% of all pregnancies worldwide are affected by preeclampsia. Preeclampsia is a major cause of pregnancy-related morbidity and mortality [1].

\footnotetext{
* Correspondence: xu_y@dr.com

${ }^{\dagger}$ Hongmei Xu and Qingyang Shi contributed equally to this work

${ }^{3}$ Department of Nephrology, the First Hospital of Jilin University, Changchun, Jilin, China

Full list of author information is available at the end of the article
}

Preeclampsia is associated with chronic systemic inflammation with activation of immune cells and increased inflammatory cytokines [2]. It has been reported that peripheral blood monocytes are highly activated in pregnant women with preeclampsia [3-5]. For instance, increased pro-inflammatory subsets of peripheral blood monocytes are correlated with the severity of preeclampsia [6]. Furthermore, peripheral blood monocytes from preeclamptic women are preferably polarized to a M1 pro-inflammatory macrophage phenotype with increased tumor necrosis factor-alpha (TNF- $\alpha$ ) and decreased interleukin (IL)-10 levels [7]. Preeclampsia is also associated with increased macrophage

(c) The Author(s). 2019 Open Access This article is distributed under the terms of the Creative Commons Attribution 4.0 International License (http://creativecommons.org/licenses/by/4.0/) which permits unrestricted use, distribution, and reproduction in any medium, provided you give appropriate credit to the original author(s) and the source, provide a link to the Creative Commons license, and indicate if changes were made. The Creative Commons Public Domain Dedication waiver (http://creativecommons.org/publicdomain/zero/1.0/) applies to the data made available in this article, unless otherwise stated. 
infiltration in the placenta with increased release of pro-inflammatory cytokines $[8,9]$. It is speculated that activation of peripheral blood monocytes contributes to enhanced inflammatory responses in placental tissue of preeclamptic women. However, the mechanism underlying the activation of peripheral blood monocytes in preeclampsia is largely unknown.

The cholinergic anti-inflammatory pathway regulates systemic inflammatory responses and plays an important role in a variety of inflammation-related disorders, such as hypertension and kidney diseases [10-12]. In the pathway, acetylcholine activates $\alpha 7$ nicotinic acetylcholine receptors $(\alpha 7 \mathrm{nAChR})$ expressed in monocytes/macrophages [13-15]. Activation of $\alpha 7 \mathrm{nAChR}$ regulates monocyte and macrophage polarization and suppresses expression of pro-inflammatory cytokines, including TNF- $\alpha$ and IL-1 $\beta$, probably through inhibition of nuclear factor $-\kappa B(N F-\kappa B)$ transcription activity $[13,16]$. It was reported that $\alpha 7 \mathrm{nAChR}$ downregulation is involved in activation of peripheral blood monocytes in various pathological conditions [17-19]. However, it is unknown whether $\alpha 7 \mathrm{nAChR}$ is involved in activation of peripheral blood monocyte in pregnant women with preeclampsia.

There is evidence showing an association between $\alpha 7 \mathrm{nAChR}$ and preeclampsia. In pregnant rats, activation of $\alpha 7 \mathrm{nAChR}$ by nicotine mitigated lipopolysaccharide (LPS)-induced placental inflammation and symptoms mimicking preeclampsia likely through suppressing the NF-kB p65 pathway [20]. Previous studies demonstrated that expression of $\alpha 7 \mathrm{nAChR}$ in the placenta was increased in pregnant women with preeclampsia compared with nonpregnant women [21-23]. These findings suggest that expression of $\alpha 7 \mathrm{nAChR}$ may be associated with placental inflammation and the development of preeclampsia. However, the role of $\alpha 7 \mathrm{nAChR}$ in the activation of peripheral blood monocytes in preeclampsia is unclear.

Taken together, we hypothesized that the $\alpha 7 \mathrm{nAChR}$ expression levels are decreased in peripheral blood monocytes of preeclamptic women and that the downregulation of $\alpha 7 \mathrm{nAChR}$ is associated with monocyte activation, enhanced inflammation, and the severity of preeclampsia. In this study, we tested the hypothesis by conducting ex vivo and in vitro experiments using isolated peripheral blood monocytes from pregnant women with preeclampsia, normotensive pregnant women, and nonpregnant women.

\section{Methods}

\section{Study population}

The Institutional Review Board of The First Hospital of Jilin University reviewed and approved the study protocol (16Y158-002). Written informed consent was obtained from all participants. The study consists of 32 normotensive and 35 preeclamptic pregnant women in the third trimester of their pregnancy and 30 age-matched nonpregnant women. Preeclampsia was defined as a combination of hypertension ( $\geq 140 / 90 \mathrm{mmHg}$ evaluated on two consecutive occasions) after the 20 weeks of gestation and proteinuria of $\geq 300 \mathrm{mg}$ in urine collected during $24 \mathrm{~h}[24,25]$. Severe preeclampsia was diagnosed by the presence of one or more of the following: systolic blood pressure $\geq 160 \mathrm{mmHg}$ or diastolic blood pressure $\geq 110 \mathrm{mmHg}$; thrombocytopenia; impaired liver function; progressive renal insufficiency; pulmonary edema; new-onset cerebral or visual disturbances [25]. Among the 35 preeclamptic pregnant women, 20 had mild preeclampsia and the other 15 had severe preeclampsia.

\section{Sample collection and preparation}

Before any medications were given, peripheral venous blood was drawn from the subjects by venipuncture and collected into heparinized tubes at the time of disease diagnosis for the normotensive and preeclamptic pregnant women and during a health checkup visit for nonpregnant women. $\mathrm{CD}_{14}{ }^{+}$monocytes were isolated immediately from the fresh whole blood samples with Ficoll's density gradient centrifugation and subsequent magnetic-activated cell sorting as described previously [26].

\section{Flow cytometry}

To study levels of surface $\alpha 7 \mathrm{nAChR}$ protein expression, the isolated monocytes were stained with anti- $\alpha 7 \mathrm{nAChR}$ antibody (1:100, ab216485, Abcam, Cambridge, MA, USA) for $30 \mathrm{~min}$ at $4{ }^{\circ} \mathrm{C}$. After washed with buffer containing $1 \%$ bovine serum albumin, the cells were incubated with Alexa 488-conjugated anti-rabbit IgG (1:500, ab150077, Abcam, Cambridge, MA, USA) for $15 \mathrm{~min}$ at room temperature. The samples were analyzed on a flow cytometer (BD Biosciences). Mean fluorescence intensity was used to quantify the surface $\alpha 7 n A C h R$ protein expression level [27].

\section{Real-time polymerase chain reaction (RT-PCR)}

Total RNA was extracted from the isolated monocytes with TRIzol reagent. RT-PCR was performed using One Step SYBR Prime Scrip RT-PCR Kit II (TaKaRa). PCR primer sequences are listed as follow: $\alpha 7 \mathrm{nAChR}$ : $\mathrm{F}$, 5'-ACA TGC GCT GCT CGC CGG GA-3'; R, 5' -GAT TGT AGT TCT TGA CCA GCT-3'; and GAPDH: F, 5'-GTC GCT GTT GAA GTC AGA GG-3'; R, 5' -GAA ACT GTG GCG TGA TGG-3'. The $\alpha 7 n A C h R$ mRNA expression was calculated by $2^{-\triangle \Delta C T}$ and normalized to GAPDH. The levels of $\alpha 7 \mathrm{nAChR}$ mRNA expression in nonpregnant women were set to a value of 1 . Each sample was run and analyzed in triplicate.

\section{Monocyte culture}

The isolated monocytes were cultured in 24-well flat-bottomed plates with RPMI 1640 medium at the density 
of $1 \times 10^{6}$ cells $/ \mathrm{mL}$. After incubated with complete medium for $18 \mathrm{~h}$, supernatant was collected for measurement of cytokines. To study stimulated cytokine release, monocytes were treated with LPS $(1 \mathrm{ng} / \mathrm{mL}$, Sigma-Aldrich, St Louis, MO, USA), and supernatant was collected for measurements of cytokines at 12,24 , and $48 \mathrm{~h}$ after LPS treatment. In another set of experiments, monocytes were treated with or without an $\alpha 7 \mathrm{nAChR}$ agonist PNU-282987 (PNU, $10 \mu \mathrm{mol} / \mathrm{L}$, Sigma-Aldrich, St Louis, MO, USA) for $24 \mathrm{~h}$; then supernatant was collected for cytokine and cells were harvested for NF- $\mathrm{kB}$ activity measurements. PNU is a highly selective $\alpha 7 \mathrm{nAChR}$ agonist $(\mathrm{Ki}=26 \mathrm{nM})$. In addition, monocytes were treated with or without an NF-kB inhibitor BAY 11-7085 $(10 \mu \mathrm{mol} / \mathrm{L}$, Sigma-Aldrich, St Louis, MO, USA) for $24 \mathrm{~h}$, and then cells were collected for NF- $\mathrm{kB}$ activity measurements. BAY 11-7085 prevents activation of NF- $\mathrm{kB}$ through irreversibly inhibiting I $\mathrm{KB} \alpha$ (the inhibitor of NF-kB) phosphorylation $(\mathrm{IC50}=10 \mu \mathrm{M})$.

\section{Enzyme-linked immunosorbent assays (ELISA)}

Protein expression of TNF- $\alpha$, IL-1 $\beta$, IL- 6 , and IL-10 in the culture medium of monocytes collected from above experiments was measured by ELISA kits (ab181421, ab46052, ab46027, ab46034, Abcam, Cambridge, MA, USA).

\section{NF-kB transcription activity assay}

Nuclear fractions of treated monocytes were extracted, and the DNA binding activity of NF-kB was detected using NF-kB p65 Transcription Factor Assay Kit (ab133112, Abcam, Cambridge, MA, USA) in accordance with manufacturer's instructions.

\section{Statistical analysis}

Statistical analysis was performed with GraphPad Prism 6.0 software (GraphPad Software Inc. San Diego, CA, USA). Continuous data are presented as mean \pm standard deviation and analyzed by one-way analysis of variance (ANOVA) or two-way ANOVA followed by Bonferroni post-test if the data had a normal distribution. Categoric variables were expressed as number and percentage of patients and analyzed with Chi-square test. Pearson correlation and linear regression were performed to examine the relationship between two parameters. Differences were considered significant at a probability level of $p<0.05$.

\section{Results \\ Patient characteristics}

The demographic and clinical characteristics of the subjects are presented in Table 1. Age was comparable among nonpregnant, normotensive pregnant, and preeclamptic pregnant women, and gestational age and parity were similar between normotensive and preeclamptic pregnant women (Table 1). Systolic and diastolic blood pressure levels were similar between nonpregnant and normotensive pregnant women but were significantly lower in these two groups than pregnant women with preeclampsia (Table 1). Levels of proteinuria and uric acid of preeclamptic women were $2.6 \pm 0.5 \mathrm{~g} / 24-\mathrm{h}$ and $6.2 \pm 0.6 \mathrm{mg} / \mathrm{dL}$, respectively, whereas proteinuria and uric acid levels of nonpregnant and normotensive pregnant were within normal ranges (Table 1).

\section{Decreased $a 7 n A C h R$ was associated with cytokine release from monocytes}

Both surface protein expression and mRNA expression levels of $\alpha 7 \mathrm{nAChR}$ in peripheral blood monocytes from preeclamptic women were significantly lower than those of nonpregnant and normotensive pregnant women (both $p<0.01$ ), while levels of $\alpha 7 \mathrm{nAChR}$ in monocytes had no difference between nonpregnant and normotensive pregnant women (Fig. 1A and B). Levels of $\alpha 7 n A C h R$ in monocytes from severe preeclamptic women trended to be, but not significantly, lower than that from mild preeclamptic women $(1.95 \pm 0.20$ vs. 2.14 $\pm 0.36, p=0.08$, student $t$-test).

Levels of TNF- $\alpha$, IL-1 $1 \beta$, and IL- 6 were increased but IL-10 was decreased in culture medium of monocytes from women with preeclampsia compared with those from nonpregnant and normotensive pregnant women (all $p<0.01$, Fig. 2A-D). There was no difference in the levels of TNF- $\alpha$,

Table 1 Characteristics of nonpregnant, normotensive pregnant, and preeclamptic women

\begin{tabular}{llll}
\hline Variable & Nonpregnant $(n=30)$ & Normotensive $(n=32)$ & Preeclamptic $(n=35)$ \\
\hline Age, years & $27.3 \pm 4.3$ & $26.3 \pm 2.8$ & $26.7 \pm 5.1$ \\
Gestational age (weeks) & N/A & $35.5 \pm 1.6$ & $35.1 \pm 1.5$ \\
Parity & N/A & $0.22 \pm 0.42$ & $0.20 \pm 0.41$ \\
Systolic BP $(\mathrm{mmHg})$ & $107.6 \pm 5.3$ & $108.8 \pm 7.1$ & $157.1 \pm 7.6^{* *}$ \\
Diastolic BP $(\mathrm{mmHg})$ & $67.5 \pm 4.5$ & $68.2 \pm 5.5$ & $107.6 \pm 7.1^{* *}$ \\
Proteinuria $(\mathrm{g} / 24 \mathrm{~h})$ & $<0.3$ & $<0.3$ & $2.6 \pm 0.5$ \\
Uric acid $(\mathrm{mg} / \mathrm{dL})$ & $3.6 \pm 0.6$ & $3.9 \pm 0.7$ & $6.2 \pm 0.6^{* *}$ \\
\hline
\end{tabular}

Data are mean \pm standard deviation. BP blood pressure. Data were analyzed using one-way ANOVA followed by Bonferroni post-test. ${ }^{* *} p<0.01$ vs. nonpregnant and normotensive pregnant groups. Proteinuria of all patients from the nonpregnant and normotensive groups was below the detection limit of the measurement 
A



B

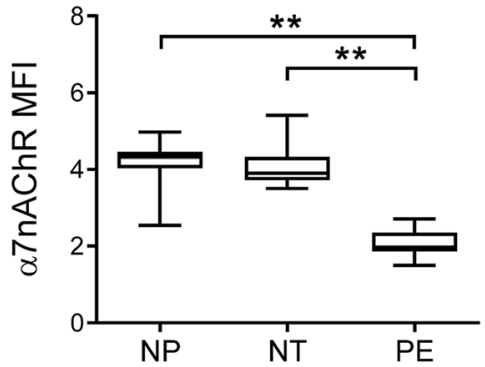

Fig. 1 Expression of a7nAChR in peripheral blood monocytes. The mRNA (a) and surface protein (b) expression of a7nAChR in peripheral blood monocytes isolated from nonpregnant (NP), normotensive pregnant (NT), and preeclamptic (PE) women was measured by RT-PCR and flow cytometry, respectively. MFI: mean fluorescence intensity. ${ }^{* *} p<0.01$ (one-way ANOVA followed by Bonferroni post-test)

IL-1 $\beta$, IL-6, and IL-10 between nonpregnant and normotensive pregnant women (Fig. 2A-D). Importantly, the protein expression levels of $\alpha 7 \mathrm{nAChR}$ in monocytes were negatively correlated with levels of systolic blood pressure $(\mathrm{r}=-0.40, p$ $=0.04$, Fig. 3A), proteinuria $(\mathrm{r}=-0.54, p<0.01$, Fig. 3B), TNF- $\alpha(\mathrm{r}=-0.42, p=0.01$, Fig. $3 \mathrm{C})$, and IL-1 $\beta(\mathrm{r}=-0.56, p$ $<0.01$, Fig. 3D), while positively correlated with the levels of IL-10 ( $r=0.43, p=0.01$, Fig. 3F). By contrast, there was no statistically significant correlation between the $\alpha 7 \mathrm{nAChR}$ and IL-6 protein levels $(r=-0.26, p=0.13$, Fig. 3E).

\section{Stimulated cytokine release in monocytes}

TNF- $\alpha$, IL- $1 \beta$, IL- 6 , and IL-10 were induced by LPS in peripheral blood monocytes isolated from nonpregnant, normotensive pregnant, and preeclamptic women (Fig. 4A-D). At 12, 24, and $48 \mathrm{~h}$ after stimulation with LPS, the levels of TNF- $\alpha$ (Fig. 4A), IL-1 $\beta$ (Fig. 4B), and IL-6 (Fig. 4C) in culture medium of monocytes from preeclamptic women were significantly higher than those from nonpregnant and normotensive pregnant women (all $p<0.01$ ). However, LPS-induced IL-10 expression levels in culture medium of monocytes were not different among the three groups (Fig. 4D).

\section{Activation of $\alpha 7 n A C h R$ partially normalized cytokine expression}

Monocytes from the three groups of women were treated with the $\alpha 7 \mathrm{nAChR}$ agonist PNU-282987. The increase of



B

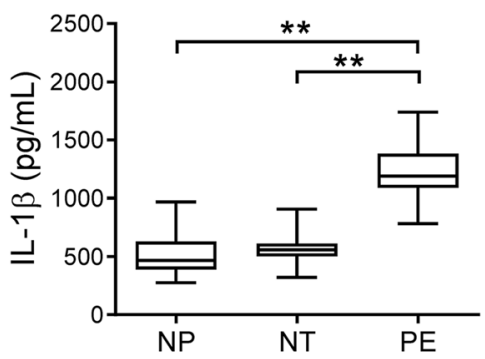

C

D
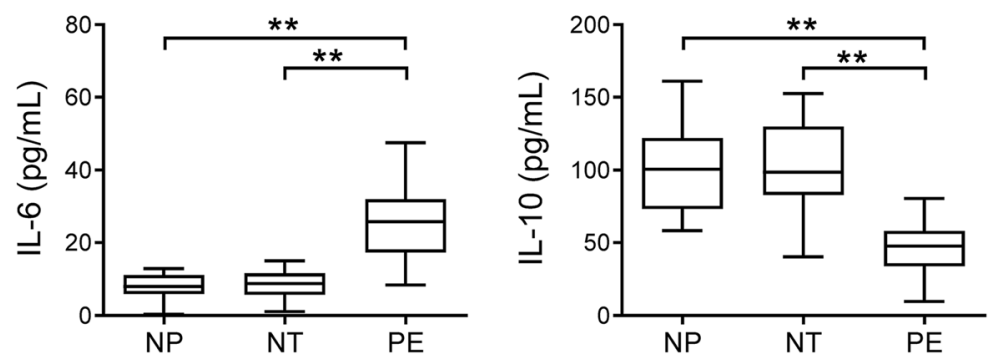

Fig. 2 Levels of cytokines in culture medium of isolated monocytes. The protein levels of TNF-a (a), IL-1 $1 \beta$ (b), IL-6 (c), and IL-10 (D) in culture medium of monocytes isolated from the peripheral blood of nonpregnant (NP), normotensive pregnant (NT), and preeclamptic (PE) women were measured. ${ }^{* *} p<0.01$ (one-way ANOVA followed by Bonferroni post-test) 
A



C

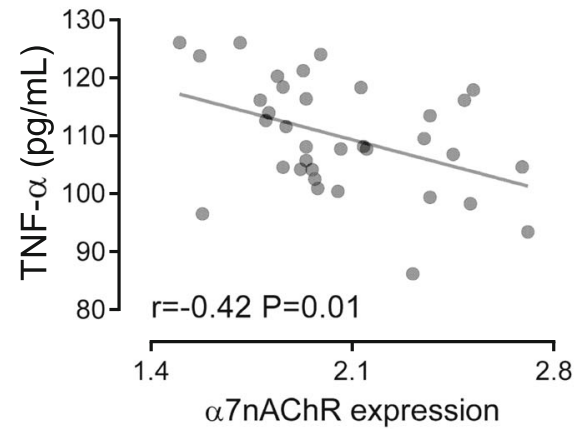

E

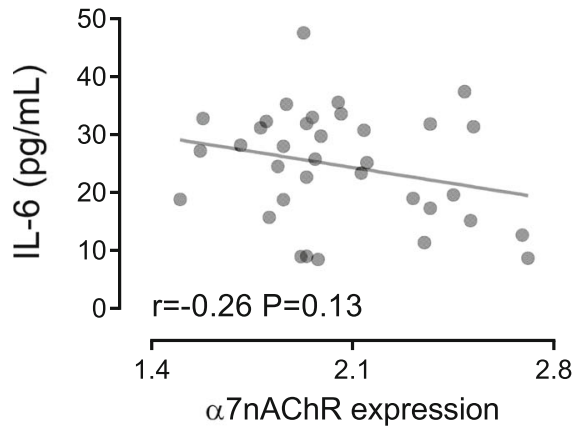

B


F

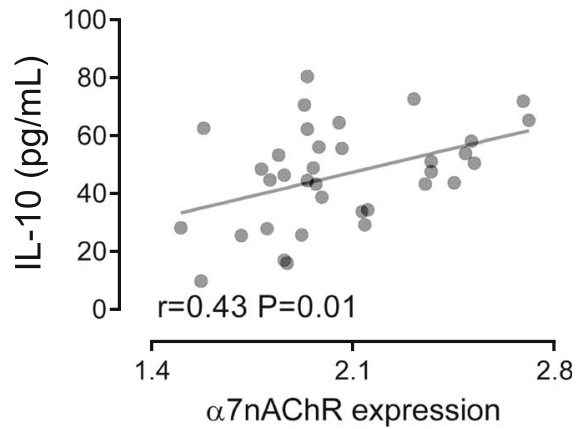

Fig. 3 Association between $\mathrm{a} 7 \mathrm{nAChR}$ and disease severity and cytokine levels in preeclampsia. The associations of the surface a7nAChR protein expression levels with systolic blood pressure (BP) (a) and proteinuria (b) of the preeclamptic women, and TNF-a (c), IL-1B (d), IL-6 (e), and IL-10 (f) levels in culture medium of monocytes isolated from the preeclamptic women were calculated. Pearson correlation and linear regression were performed

TNF- $\alpha$ (Fig. 5A), IL-1 $\beta$ (Fig. 5B), and IL-6 (Fig. 5C) levels in culture medium of monocytes from preeclamptic women was significantly attenuated by PNU-282987 treatment (all $p<0.01$ ). Furthermore, the decrease of IL-10 levels in preeclamptic women was also partially reversed by PNU-282987 (Fig. 5D, $p<0.01$ ).

\section{NF-KB transcription activity}

The DNA binding activity of NF-kB was enhanced in monocytes from preeclamptic women compared with those from nonpregnant and normotensive pregnant women $(p<0.01)$, and this enhanced activity was abolished by BAY 11-7085 treatment $(p<0.01)$ (Fig. 6A). Interestingly, the enhanced $\mathrm{NF}-\mathrm{kB}$ transcription activity in monocytes from preeclamptic women was also reversed by PNU-282987 treatment ( $p<0.01$, Fig. $6 \mathrm{~B})$.

\section{Discussion}

In this study, we demonstrated a significant association between preeclampsia and downregulation of $\alpha 7 \mathrm{nAChR}$ in peripheral blood monocytes, suggesting that preeclampsia is related to impaired cholinergic anti-inflammatory 
A

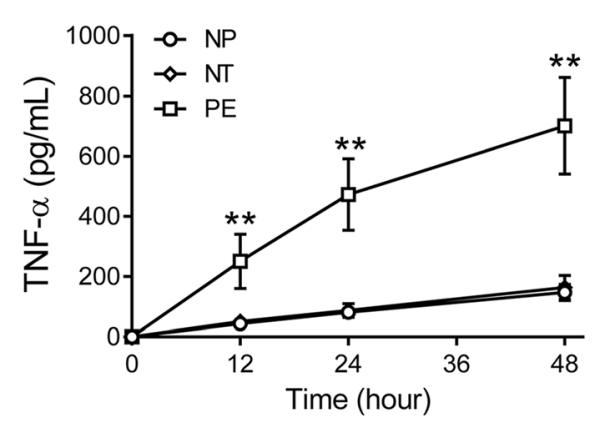

C

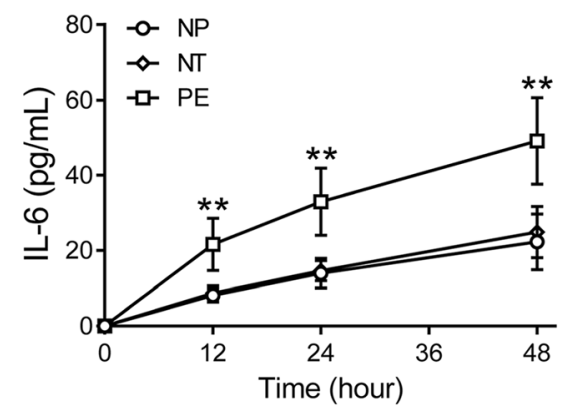

B



D

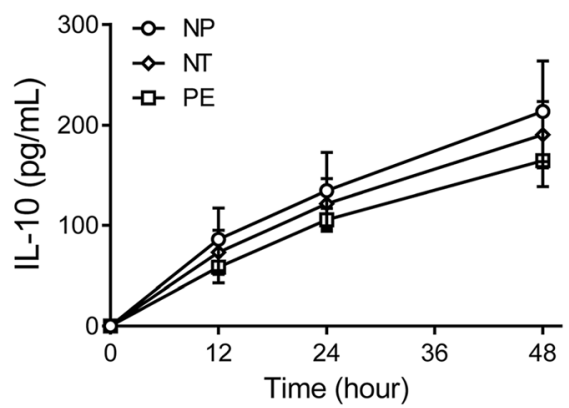

Fig. 4 Lipopolysaccharides (LPS)-induced cytokine release from isolated monocytes. Peripheral blood monocytes were isolated from nonpregnant $(N P)$, normotensive pregnant (NT), and preeclamptic (PE) women and stimulated with LPS for 12, 24, or 48 h, then TNF-a (a), IL-1 3 (b), IL-6 (c), and IL-10 (d) levels in the supernatant were measured. ${ }^{*} p<0.01$ vs. NP or NT groups at the same time points (one-way ANOVA followed by Bonferroni post-test)

pathway. Furthermore, we found that the $\alpha 7 \mathrm{nAChR}$ expression levels were closely correlated with the severity of preeclampsia in terms of blood pressure and proteinuria levels. Previously, $\alpha 7 \mathrm{nAChR}$ downregulation was identified in inflammation-related diseases, especially in other types of hypertension [12]. The present study for the first time linked $\alpha 7 \mathrm{nAChR}$ downregulation in circulatory monocytes to pregnancy-induced hypertension. This result is different from previous studies which demonstrated that $\alpha 7 \mathrm{nAChR}$ was upregulated in the placental tissue of women with preeclampsia [21-23]. This difference suggests that the change of $\alpha 7 \mathrm{nAChR}$ expression in preeclampsia is tissue specific.

It is also possible that the downregulation of $\alpha 7 \mathrm{nAChR}$ in circulatory monocytes we found in the present study may not reflect the overall state of the $\alpha 7 \mathrm{nAChR}$ expression in pregnant women with preeclampsia. Anyway, these findings suggest that downregulation of $\alpha 7 \mathrm{nAChR}$ may be associated with the development of pregnancy-induced hypertension and preeclampsia. It is still unclear whether downregulation of $\alpha 7 \mathrm{nAChR}$ precedes onset of preeclampsia. Further studies addressing this question may help to reveal a possible causative relationship between $\alpha 7 \mathrm{nAChR}$ and preeclampsia. It was reported that knockout of $\alpha 7 \mathrm{nAChR}$ exacerbated hypertension in mouse 2-kidney 1-clip model and worsened hypertensive renal injury [28], suggesting that impairment of the cholinergic anti-inflammatory pathway predisposes to hypertension and target organ damage. However, whether $\alpha 7 \mathrm{nAChR}$ downregulation is required for preeclampsia needs further investigation.

$\alpha 7 \mathrm{nAChR}$ may serve as a therapeutic target for pregnancy-induced hypertension and preeclampsia. Animal studies demonstrated that activation of $\alpha 7 \mathrm{nAChR}$ with nicotine significantly attenuated preeclampsia-like symptoms induced by LPS in pregnant rats [20]. $\alpha 7 \mathrm{nAChR}$ agonists also demonstrated anti-hypertensive and kidney-protective effects in other animal models. For example, activation of $\alpha 7 \mathrm{nAChR}$ with nicotine lowered blood pressure in a mouse model of lupus-induced hypertension [10, 29]. However, chronic administration with the $\alpha 7 \mathrm{nAChR}$ agonist PNU-282987 did not significantly alter arterial blood pressure of spontaneously hypertensive rats [28]. In contrast, removal of the cholinergic-sympathetic pathway by coeliac vagotomy prevented angiotensin II-induced hypertension in mice [30]. Therefore, the blood pressure-regulatory role of $\alpha 7 \mathrm{nAChR}$ is various and model-dependent. The therapeutic effects of $\alpha 7 \mathrm{nAChR}$ on pregnancy-induced hypertension and preeclampsia are still elusive.

In the present study, we demonstrated that $\alpha 7 \mathrm{nAChR}$ expression levels were associated with levels of 
A

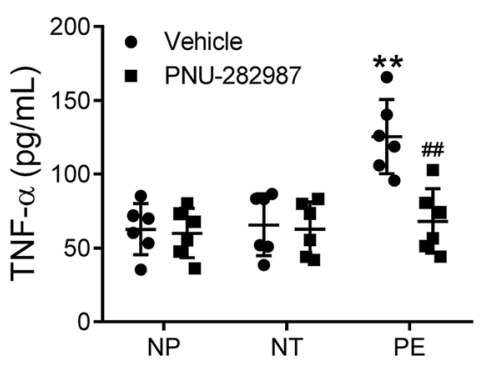

C

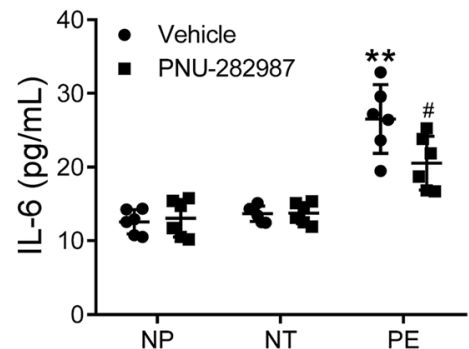

B

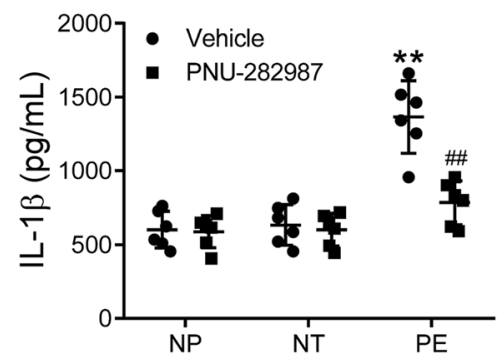

D

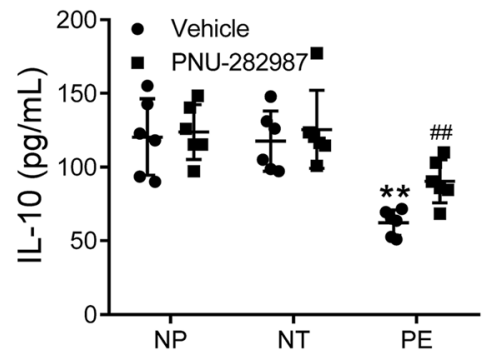

Fig. 5 Effects of a7nAChR activation on monocyte cytokine release. Peripheral blood monocytes isolated from nonpregnant (NP), normotensive pregnant (NT), and preeclamptic (PE) women were treated with or without an a7nAChR agonist PNU-282987 for $24 \mathrm{~h}$, then TNF-a (a), IL-1 $\beta$ (b), IL-6 (c), and IL-10 (d) levels in the supernatant were measured. ${ }^{* *} p<0.01$ vs. the vehicle group of the NP and NT groups; ${ }^{\#} p<0.05$, ${ }^{\# \#} p<0.01$ vs. the PE group treated with vehicle (two-way ANOVA followed by Bonferroni post-test, groups of NP, NT and PE were entered as the betweensubjects factor, treatments of vehicle and PNU-282987 were entered as the within-subjects factor)

pro-inflammatory cytokines (TNF- $\alpha$ and IL-1 $\beta$ ) as well as the anti-inflammatory cytokine (IL-10). Previous studies showed that activation of $\alpha 7 \mathrm{nAChR}$ regulated polarization of macrophages and promoted conversion of classically activated, pro-inflammatory M1 to alternatively activated, anti-inflammatory M2 macrophages [31-33]. Taken together, these findings suggest that downregulation of $\alpha 7 \mathrm{nAChR}$ may polarize more M1 but less M2 macrophages, resulting in increased M1 cytokines (TNF- $\alpha$ and IL-1 $\beta$ ) and decreased M2 cytokines such as IL-10. In this study, the $\alpha 7 \mathrm{nAChR}$ expression level in monocytes was not associated with the IL-6 level. As reported, IL-6 acts as both a pro-inflammatory and an anti-inflammatory cytokine and can be synthesized and released by both M1 and M2 macrophages [34-36]. This may be a reason for the nonsignificant association between $\alpha 7 n A C h R$ and IL- 6 in monocytes.

Not only the baseline release of pro-inflammatory cytokines from peripheral blood monocytes was increased in preeclampsia, LPS-induced TNF- $\alpha$, IL-1 $\beta$, and IL-6 release was also enhanced in women with preeclampsia. LPS-induced cytokine synthesis and release are majorly


Fig. 6 NF-KB activity. Peripheral blood monocytes isolated from nonpregnant (NP), normotensive pregnant (NT), and preeclamptic (PE) women were treated with or without an NF-KB inhibitor BAY 11-7085 (a) or a7nAChR agonist PNU-282987 (b) for $24 \mathrm{~h}$, then the DNA binding activity of NF-KB was measured. ${ }^{* *} p<0.01$ vs. the vehicle group of the NP and NT groups; ${ }^{\# \#} p<0.01$ vs. the PE group treated with vehicle (two-way ANOVA followed by Bonferroni post-test, groups of NP, NT and PE were entered as the between-subjects factor, treatments of vehicle and BAY 11-7085 or PNU-282987 were entered as the within-subjects factor) 
mediated by activation of NF- $\mathrm{kB}[37,38]$. Therefore, our findings suggest that the NF- $\mathrm{KB}$ pathway is primed to synthesize pro-inflammatory cytokines in monocytes in preeclampsia. This speculation was confirmed by NF- $\mathrm{kB}$ activity measurements. LPS stimulation may be different from the inflammatory state in preeclampsia as IL-10 was upregulated by LPS while was downregulated in preeclampsia, which might be why LPS-induced IL-10 was not enhanced in preeclampsia.

Our in vitro experiments demonstrated that activation of $\alpha 7 n A C h R$ with PNU-282987 inhibited NF- $\mathrm{kB}$ activation and corrected pro- and anti-inflammatory cytokine expression in monocytes from preeclamptic women. These findings suggest that PNU-282987-caused reverse of cytokine expression is most likely mediated by suppressing the NF- $\kappa B$ pathway.

One of the limitations of the present study is that we could not provide a causative relationship between $\alpha 7 \mathrm{nAChR}$ downregulation and preeclampsia. A future longitudinal study with multiple test timepoints may help to establish the role of $\alpha 7 \mathrm{nAChR}$ downregulation in the development of preeclampsia. We failed to show a significant downregulation of $\alpha 7 \mathrm{nAChR}$ in severe preeclampsia compared with mild preeclampsia, which might be due to the relatively small sample size.

\section{Conclusion}

In conclusion, the findings in this study indicate that downregulation of $\alpha 7 \mathrm{nAChR}$ in peripheral blood monocytes may be associated with the development of pregnancy-induced hypertension and preeclampsia through activating NF- $\mathrm{kB}$ and increasing pro-inflammatory and decreasing anti-inflammatory cytokine release.

\section{Abbreviations \\ IL: Interleukin; LPS: Lipopolysaccharides; NF-KB: Nuclear factor-kB; NP: Nonpregnant; NT: Normotensive pregnant; PE: Preeclamptic; PNU: PNU-282987; TNF-a: Tumor necrosis factor-alpha; a7nAChR: a7 nicotinic acetylcholine receptor}

\section{Acknowledgements}

Not applicable.

\section{Funding}

There is no any funding to support this study.

\section{Availability of data and materials}

The data are available from the corresponding author on reasonable request.

\section{Authors' contributions}

Conceived and designed the experiments: HX, YX. Performed the experiments: HX, QS, YM. Collection the data: HX, QS, YM. Analyzed the data: $H X, L W$, JG. Wrote the paper: HX, YX. All authors have read and approved the final manuscript.

\section{Ethics approval and consent to participate}

The Institutional Review Board of The First Hospital of Jilin University reviewed and approved the study protocol (16Y158-002). Written informed consent was obtained from all participants.
Consent for publication

Not applicable.

\section{Competing interests}

The authors declare that they have no competing interests.

\section{Publisher's Note}

Springer Nature remains neutral with regard to jurisdictional claims in published maps and institutional affiliations.

\section{Author details}

'Department of Obstetrics, the First Hospital of Jilin University, Changchun, Jilin, China. ${ }^{2}$ Center for Prenatal Diagnosis, the First Hospital of Jilin University, Changchun, Jilin, China. ${ }^{3}$ Department of Nephrology, the First Hospital of Jilin University, Changchun, Jilin, China.

Received: 20 December 2018 Accepted: 13 May 2019

Published online: 28 May 2019

\section{References}

1. LaMarca B, Cornelius DC, Harmon AC, Amaral LM, Cunningham MW, Faulkner JL, Wallace K. Identifying immune mechanisms mediating the hypertension during preeclampsia. Am J Physiol Regul Integr Comp Physiol. 2016;311(1):R1-9.

2. Harmon AC, Cornelius DC, Amaral LM, Faulkner JL, Cunningham MW Jr, Wallace K, LaMarca B. The role of inflammation in the pathology of preeclampsia. Clin Sci (Lond). 2016;130(6):409-19.

3. McCord N, Ayuk P, McMahon M, Boyd RC, Sargent I, Redman C. System y+ arginine transport and $\mathrm{NO}$ production in peripheral blood mononuclear cells in pregnancy and preeclampsia. Hypertension. 2006;47(1):109-15.

4. Faas MM, Spaans F, De Vos P. Monocytes and macrophages in pregnancy and pre-eclampsia. Front Immunol. 2014;5:298.

5. Faas MM, de Vos P. Maternal monocytes in pregnancy and preeclampsia in humans and in rats. J Reprod Immunol. 2017;119:91-7.

6. Tang MX, Zhang YH, Hu L, Kwak-Kim J, Liao AH. CD14++ CD16+ HLA-DR+ monocytes in peripheral blood are quantitatively correlated with the severity of pre-eclampsia. Am J Reprod Immunol. 2015;74(2):116-22.

7. Medeiros LT, Peracoli JC, Bannwart-Castro CF, Romao M, Weel IC, Golim MA de Oliveira LG, Kurokawa CS, Medeiros Borges VT, Peracoli MT. Monocytes from pregnant women with pre-eclampsia are polarized to a M1 phenotype. Am J Reprod Immunol. 2014;72(1):5-13.

8. Przybyl L, Haase N, Golic M, Rugor J, Solano ME, Arck PC, Gauster M, Huppertz B, Emontzpohl C, Stoppe C, et al. CD74-downregulation of placental macrophagetrophoblastic interactions in preeclampsia. Circ Res. 2016;119(1):55-68.

9. Zhang $Y$, Yang H, Long Y, Ma Q, Chen R. Plasma level of placenta-derived macrophage-stimulating protein -chain in preeclampsia before 20 weeks of pregnancy. PLoS One. 2016;11(8):e0161626.

10. Fairley AS, Mathis KW. Cholinergic agonists reduce blood pressure in a mouse model of systemic lupus erythematosus. Physiol Rep. 2017;5(7).

11. Inoue T, Tanaka S, Okusa MD. Neuroimmune interactions in inflammation and acute kidney injury. Front Immunol. 2017:8:945.

12. Chen JK, Zhao T, Ni M, Li DJ, Tao X, Shen FM. Downregulation of alpha7 nicotinic acetylcholine receptor in two-kidney one-clip hypertensive rats. BMC Cardiovasc Disord. 2012;12:38.

13. Tracey KJ. Reflex control of immunity. Nat Rev Immunol. 2009;9(6):418-28.

14. van Maanen MA, Vervoordeldonk MJ, Tak PP. The cholinergic antiinflammatory pathway: towards innovative treatment of rheumatoid arthritis. Nat Rev Rheumatol. 2009;5(4):229-32.

15. Baez-Pagan CA, Delgado-Velez M, Lasalde-Dominicci JA. Activation of the macrophage alpha7 nicotinic acetylcholine receptor and control of inflammation. J Neurolmmune Pharmacol. 2015;10(3):468-76.

16. Patel H, Mclntire J, Ryan S, Dunah A, Loring R. Anti-inflammatory effects of astroglial alpha7 nicotinic acetylcholine receptors are mediated by inhibition of the NF-kappaB pathway and activation of the Nrf2 pathway. J Neuroinflammation. 2017;14(1):192.

17. Perl O, Ilani T, Strous RD, Lapidus R, Fuchs S. The alpha7 nicotinic acetylcholine receptor in schizophrenia: decreased mRNA levels in peripheral blood lymphocytes. FASEB J. 2003;17(13):1948-50.

18. Cedillo JL, Arnalich F, Martin-Sanchez C, Quesada A, Rios JJ, Maldifassi MC, Atienza G, Renart J, Fernandez-Capitan C, Garcia-Rio F, et al. Usefulness of alpha7 nicotinic receptor messenger RNA levels in peripheral blood mononuclear cells as a 
marker for cholinergic antiinflammatory pathway activity in septic patients: results of a pilot study. J Infect Dis. 2015;211(1):146-55.

19. Hamano R, Takahashi HK, Iwagaki H, Yoshino T, Nishibori M, Tanaka N. Stimulation of alpha7 nicotinic acetylcholine receptor inhibits CD14 and the toll-like receptor 4 expression in human monocytes. Shock. 2006;26(4):358-64.

20. Liu Y, Yang J, Bao J, Li X, Ye A, Zhang G, Liu H. Activation of the cholinergic anti-inflammatory pathway by nicotine ameliorates lipopolysaccharide-induced preeclampsia-like symptoms in pregnant rats. Placenta. 2017;49:23-32.

21. Zheng L, Shi L, Zhou Z, Chen X, Wang L, Lu Z, Tang R. Placental expression of AChE, alpha7nAChR and NF-kappaB in patients with preeclampsia. Ginekol Pol. 2018;89(5):249-55.

22. Kwon JY, Kim YH, Kim SH, Kang MH, Maeng YS, Lee KY, Park YW. Difference in the expression of alpha 7 nicotinic receptors in the placenta in normal versus severe preeclampsia pregnancies. Eur J Obstet Gynecol Reprod Biol. 2007:132(1):35-9.

23. Machaalani R, Ghazavi E, David RV, Hinton T, Makris A, Hennessy A. Nicotinic acetylcholine receptors (nAChR) are increased in the pre-eclamptic placenta. Hypertens Pregnancy. 2015;34(2):227-40.

24. Brown MA, Magee LA, Kenny LC, Karumanchi SA, McCarthy FP, Saito S, Hall DR, Warren CE, Adoyi G, Ishaku S, et al. The hypertensive disorders of pregnancy: ISSHP classification, diagnosis \& management recommendations for international practice. Pregnancy Hypertens. 2018;13:291-310.

25. American College of $\mathrm{O}$. Gynecologists, task force on hypertension in $\mathrm{P}$ : hypertension in pregnancy. Report of the American College of Obstetricians and Gynecologists' task force on hypertension in pregnancy. Obstet Gynecol. 2013;122(5):1122-31.

26. Vijayan D. Isolation and differentiation of monocytes-macrophages from human blood. Methods Mol Biol. 2012;844:183-7.

27. Koval L, Kalashnyk O, Lykhmus O. Skok M: alpha7 nicotinic acetylcholine receptors are involved in suppression of the antibody immune response. J Neuroimmunol. 2018;318:8-14.

28. Li DJ, Evans RG, Yang ZW, Song SW, Wang P, Ma XJ, Liu C, Xi T, Su DF, Shen FM. Dysfunction of the cholinergic anti-inflammatory pathway mediates organ damage in hypertension. Hypertension. 2011;57(2):298-307.

29. Mathis KW. An impaired neuroimmune pathway promotes the development of hypertension in systemic lupus erythematosus. Am J Physiol Regul Integr Comp Physiol. 2015;309(9):R1074-7.

30. Carnevale D, Perrotta M, Pallante F, Fardella V, lacobucci R, Fardella S, Carnevale L, Carnevale R, De Lucia M, Cifelli G, et al. A cholinergicsympathetic pathway primes immunity in hypertension and mediates brainto-spleen communication. Nat Commun. 2016;7:13035.

31. Han Z, Shen F, He Y, Degos V, Camus M, Maze M, Young WL, Su H. Activation of alpha-7 nicotinic acetylcholine receptor reduces ischemic stroke injury through reduction of pro-inflammatory macrophages and oxidative stress. PLoS One. 2014;9(8):e105711.

32. Kalkman HO, Feuerbach D. Modulatory effects of alpha7 nAChRs on the immune system and its relevance for CNS disorders. Cell Mol Life Sci. 2016; 73(13):2511-30.

33. Zhang Q, Lu Y, Bian H, Guo L, Zhu H. Activation of the alpha7 nicotinic receptor promotes lipopolysaccharide-induced conversion of M1 microglia to M2. Am J Transl Res. 2017;9(3):971-85.

34. Scheller J, Chalaris A, Schmidt-Arras D, Rose-John S. The pro- and antiinflammatory properties of the cytokine interleukin-6. Biochim Biophys Acta. 2011;1813(5):878-88.

35. Martinez FO, Gordon $\mathrm{S}$. The $\mathrm{M} 1$ and $\mathrm{M} 2$ paradigm of macrophage activation: time for reassessment. F1000Prime Rep. 2014;6:13.

36. Fuster JJ, Walsh $\mathrm{K}$. The good, the bad, and the ugly of interleukin- 6 signaling. EMBO J. 2014;33(13):1425-7.

37. Andreakos E, Sacre SM, Smith C, Lundberg A, Kiriakidis S, Stonehouse T, Monaco C, Feldmann M, Foxwell BM. Distinct pathways of LPS-induced NFkappa B activation and cytokine production in human myeloid and nonmyeloid cells defined by selective utilization of MyD88 and mal/TIRAP. Blood. 2004;103(6):2229-37.

38. Sharif O, Bolshakov VN, Raines S, Newham P, Perkins ND. Transcriptional profiling of the LPS induced NF-kappaB response in macrophages. BMC Immunol. 2007;8:1.

\section{Ready to submit your research? Choose BMC and benefit from:}

- fast, convenient online submission

- thorough peer review by experienced researchers in your field

- rapid publication on acceptance

- support for research data, including large and complex data types

- gold Open Access which fosters wider collaboration and increased citations

- maximum visibility for your research: over $100 \mathrm{M}$ website views per year

At BMC, research is always in progress.

Learn more biomedcentral.com/submissions 